\title{
Scientists should explore alternatives to flying
}

\author{
The trade-off between necessary scientific communication and the associated $\mathrm{CO}_{2}$ footprint asks for a thorough \\ reconsideration of our travelling habits, new institutional travelling policies and for alternative approaches to \\ interaction with colleagues and peers.
}

T he evidence for the man-made contribution to climate change is overwhelming and the vast majority of climate experts have little doubt about the impact of civilization-caused emission of $\mathrm{CO}_{2}$ on global warming. It is no longer the question 'if' but 'how much' the temperature on our planet will rise in the next few decades. Yet, the behaviour of a good share of scientists around the globe does not reflect this awareness when it comes to science-related travelling and somehow contradicts the plea to drastically cut down $\mathrm{CO}_{2}$ emissions worldwide. Perhaps that same scientific community should instead showcase alternative behaviour and become a role model for the necessary changes.

We may buy organic food, use electricity from alternative energies and cycle or take public transport instead of driving. Yet, when it comes to flying, we refrain from reflecting on our behaviour. For many universities and scientific institutions travel contributes about $50 \%$ of all greenhouse gas emission; of this $50 \%$ flights usually take a share of more than $90 \%$. A round-trip from Berlin to San Francisco produces 1.3 tonnes of $\mathrm{CO}_{2}$ per economy class passenger, but taking into account contrails, other greenhouse gases emitted and the emission at high altitude, this corresponds to a $\mathrm{CO}_{2}$ equivalent of about 3 tonnes. To put this into perspective, the carbon dioxide budget per capita is estimated to be around 1.6 tonnes per year to keep the global temperature rise within the $2{ }^{\circ} \mathrm{C}$ goal of the Paris agreement ${ }^{1}$.

Sadly, reducing travelling, and air travel in particular, seems unfeasible. Scientists are concerned that if they cut down on travel, they will not progress in their careers, they will lose contact with theirs peers and their papers may even be cited less ${ }^{2}$. Yet, a direct link between travelling and academic success is far from demonstrated. For example, in a case study at the University of British Columbia, researchers couldn't find evidence that frequent flying would impact metrics of academic productivity such as the adjusted h-index (while there was evidence for a relation to salary) ${ }^{3}$. The consequences of visiting fewer conferences might therefore be less dramatic than feared.

One option to reduce the impact of flying is contributing to a carbon-offset scheme.

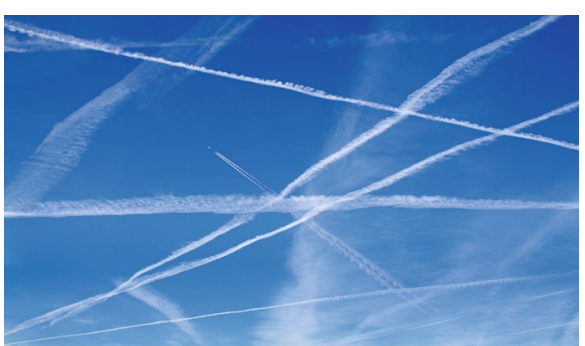

Credit: Jon Bower UK/Alamy Stock Photo

However, this is a short-term workaround and cannot be used as a justification for flying inconsiderately. For the longer term, scientists should start exploring different routes. For starters, local conferences that can be reached by train rather than by aeroplane could be favoured over global ones.

International speakers could give live video presentations. The same applies to speakers at institutional seminars and colloquia, and we could improve the experience by making better use of innovations such as virtual reality environments.

There are alternatives to conventional conferences that have a drastically reduced climate impact. Virtual conferences, partially inspired by the success of virtual worlds like Second Life, have been tested and showcased for at least ten years ${ }^{4}$, but transfer to the real science world has been limited. Arguably, interaction through video screens or avatars seems less productive compared to a vis-à-vis, and a virtual drink at a virtual bar doesn't sound like much fun. Yet, these concepts provide a range of benefits beyond saved greenhouse gas emissions that may outbalance the disadvantages. They not only save resources and valuable travel time, which could instead be spent in the lab, in discussion with co-workers and students, or with friends and family for a better worklife balance, but they also provide a lowbarrier access, which is especially valuable for scientists with little budget or from remote regions.

The above considerations apply to the editors of this journal, too. We depend on interaction with scientific communities. We fly to conferences to learn about the timely questions in a field and the latest findings, and to get in touch with researchers. We also visit research institutions to gain insights on new projects and research directions. We are not going to stop flying altogether, but we are currently considering alternative approaches: video conference calls instead of lab visits, prioritizing regional to overseas conferences and train rides to flights, even if it increases travelling time.

Scientists around the globe ask for drastic measures to limit $\mathrm{CO}_{2}$ emission ${ }^{5}$. And yes, it is the responsibility of politicians to implement the framework, to lead and moderate the societal changes urgently needed. But scientists should act, too. Truly, if scientists stopped flying from one day to another, this wouldn't reduce the global $\mathrm{CO}_{2}$ emission by any significant digit. But the same can be said for every individual measure taken to reduce $\mathrm{CO}_{2}$ emission and only the sum of all can make a change. More importantly, by reducing the number of trips taken, and initiating and promoting alternatives to conference travel, the scientific community can become a role model showcasing new ways of global collaboration. To this end, besides critically reconsidering our personal tradeoff between scientific needs and climate impact, we need to push institutions and companies, but also funding agencies and scientific societies, to implement sustainable travelling policies taking into account the $\mathrm{CO}_{2}$ emissions. Our personal responsibility needs a framework that no longer sanctions, but promotes the right choices ${ }^{2}$. We shouldn't take the status quo of science communication as a natural law, but as in a state of continuous change. We as scientists and science communicators have a responsibility to shape this state for the good of science and of mankind.

Published online: 5 September 2019

https://oi.org/10.1038/s41565-019-0546-3

References

1. O'Neill, D. W., Fanning, A. L., Lamb, W. F. \& Steinberger, J. K. Nat. Sustain. 1, 88-95 (2018).

2. Nursey-Bray, M., Palmer, R., Meyer-Mclean, B., Wanner, T. \& Birzer, C. Sustainability 11, 2694 (2019).

3. Wynes, S., Donner, S. D., Tannason, S. \& Nabors, N. J. Cleaner Prod. 226, 959-967 (2019).

4. Welch, C. J., Ray, S., Melendez, J., Fare, T. \& Leach, M. Nat. Chem. 2, 148-152 (2010).

5. Hagedorn, G. et al. Science 364, 139-140 (2019). 